\title{
Cloud Solution to assist in Mobile Technology Learning
}

\author{
Mohamad Tabbara (Corresponding Author) \\ Higher Colleges of Technology, United Arab Emirates. E-mail: mtabbara@hct.ac.ae
}

Received: March 19, 2014 Accepted: April 7, 2014 Published: April 7, 2014

doi:10.5296/jet.v1i2.5315 URL: http://dx.doi.org/10.5296/jet.v1i2.5315

\begin{abstract}
This paper will discuss the use of cloud-based computing solutions to assist in the process of mobile learning and teaching. The paper will go through the limitations of mobile technology and the areas where cloud solutions can assist to fill in the gaps. It will also discuss the student's acceptance of such system and the tremendous opportunities cloud technology could offer to higher education students in terms of learning mobility and computer software accessibility. In this respect, the paper will investigate the usage of the Virtual Desktop Infrastructure (VDI) that is recently adapted in the Higher Colleges of Technology (HCT) as part of its private cloud solution. This research will show how using cloud solutions in conjunction with mobile smart devices, such as the iPad, could technically and pedagogically facilitate the educational process both for students and faculty members. Concluding remarks will be presented and discussed at the end of the paper.
\end{abstract}

Keywords: virtualize educational system, cloud based computing solution, cloud solution in higher education

\section{Introduction}

The Higher Colleges of Technology (HCT) has Over 20000 students attending 17 different campuses throughout the UAE where they study over 40 different work-relevant, career programmes in Engineering Technology, Computer \& Information Science (CIS), Health Sciences, Business, Applied Communications and Education. Each academic program within the HCT offers huge amount of courses accompanied with recommended software/hardware for training and practical sessions. HCT has a commitment to establish a new system of post-secondary education for UAE Nationals that is built through cutting edge technology for the provision of advanced education to all Nationals who want to develop their educational potentials. Therefore the HCT stresses the ideals of educational mobility, continuous productivity, and excellence throughout all its programs. Inconsequence to that, at the beginning of the academic year September 2012, the HCT made it obligatory to all its incoming 1700 students in addition to its teaching faculties and returning students to buy their own iPad's and start course delivery and teaching solely using the iPad platform. This will 
allow the HCT to move its traditional computer labs based learning into more dynamic mobile smart technology environment. At this point, regardless of the many advantages in terms of portability and application accessibility the iPad offers, extremely serious concerns were floating to the surface in terms of the iPad proprietorship software and its incapability of running neither multiple Operating System platforms nor other competitors' application software. In addition to that, the overall numbers of both students and applications running in the HCT were growing very rapidly, and the sharing of learning materials and coursework in a secure manner was periodically compromised. In this respect, all sort of data stored on board of student's laptops were forming a continuous concern for administration in terms of data protection and integrity. Moreover, the additional physical computer machines needed in the labs to accommodate the growing numbers of students were causing an excessive overhead cost for the administration. Katz's 2008 research on cloud computing and its effect on empowering employees stated the following: Empowerment of the individual is reducing the individual's reliance on traditional brick-and-mortar institutions in favor of new and emerging virtual ones. Second, ubiquitous access to high-speed networks along with network standards, open standards and content, and techniques for virtualizing hardware, software, and services is making it possible to leverage scale economies in unprecedented ways. (p. 263)

In an attempt to tackle the above problems, the CIS department in Abu Dhabi Campuses setup its own private cloud based computing solution. The HCT cloud hosts its own virtual machines in corporation with HUAWEI enterprise and uses Virtual Desktop Infrastructure (VDI) to allow both students and faculties to connect using Thin Clients (TC) or any other smart devices including the iPads to the HCT virtualized servers and applications. In this respect, users can access multiple Operating System platforms and use any customised or off-the-shelf application regardless of its compatibility with the apple iOS or any other smart device's platform.

The aim of this paper is to highlight the limitation of standard mobile technology in education and show how the usage of customized cloud based solution such as the one implemented at the HCT can help tackling and complementing mobile technology usage. In addition to that, this research will show how the HCT cloud solution is facilitating the overall usage of iPads and making it a holistic solution that fits every program curriculum. Also it will demonstrate how using cloud solution within higher education can cut the cost of establishing dedicated labs and bring down the overall IT infrastructure cost.

The next section will discuss the educational uses of cloud solution in general, and present examples of the HCT cloud solution and its usage. Section 3 will present the results of a survey given to students currently using the HCT cloud. Section 4 will present technical information on the VDI solution and future expansion planes. Section 5 will discuss the utilisation of this technology within the HCT and compare it to traditional usage of labs with desktop or laptops machines in terms of cost and accessibility. Concluding remarks will be presented at the end of the paper. 


\section{Cloud Solution in the HCT}

Cruise (2013) stated that "the technology provides an innovative alternative to bricks-and-mortar schooling, enabling personal learning, interactive learning and many-to-many learning. The cloud also allows students to interact and collaborate with an ever-expanding circle of their peers, regardless of geographical location.” (p. 3-4)

Prior to the rise of the cloud computing, many educational paradigms were solely depending on one proprietorship technology. Slowly in the last 5 years, within the introduction of educational cloud computing solutions, technology became less and less the work of the professor, rather it was thought as a mean to make teaching more efficient, and to enable the teaching staff to do more with the same resources. In today's modern technology there are tremendous amount of applications that are floating around and can be used to enhance student's chances of better learning. This rapid growth of applications makes it very difficult to bind teaching curriculums to one brand or vendor. Therefore, in an everlasting fast growing software market a modern educational curriculum should be ready to adapt its teaching methodologies and lab's manuals to many platforms and multiple software vendors and be ready to change at any time. For example, most of the courses in the CIS department within the HCT run in accordance with international standards and regulating bodies such as CISCO, SYMANTEC, CIPS \& ABET and many others. These institutes set the labs criteria's and in some cases dictate the software applications that must be used within. In this respect many OS's/application software are needed to run the labs manuals and in many cases these OS's and programs are neither supported by the iPad's iOS nor the vendors on the app store. This causes a major problem to the overall operation of the labs and courses in general especially that new registered students and faculties are both using their iPads solely to receive and deliver the courses. In consequence to that, many students studying here in the HCT has their own laptops that they use for educational and personal purposes. The data on these computers are in many cases under threats from many factors such as data loose, failure of hard disks, cyber theft and viruses malfunction. In this respect, HCT has set up its own private cloud solution that can offer virtual desktops connectivity for 100 consecutive users ready for expansion on need. The solution incorporate 3 physically labs in its Abu Dhabi 3 campuses that offer 60 dedicated VDI stations. Each station consist of a Thin Client (TC) that is a connectivity box that acts as a linkage between the end-user and the virtualization servers running on the HCT private cloud. In consequence to the dedicated VDI labs, students can use their own smart mobile devices, including their iPads to connect directly to the HCT cloud and access all the application and services. As a result, students and faculties can access all the software and Operating Systems needed for courses delivery either from the VDI stations or from their iPads/smart mobile devices of their choice. Mobile users can access the HCT cloud by installing small third party client software that works as a connector/authenticator. The HCT is using CITRIX receiver that can be installed for free from any mobile smart device. CITRIX offers its linkage services to many clients with different platforms and form factors. As a result, any smart mobile device running Windows 8, iOS, Android, or Blackberry OS can access the HCT designated cloud solution and log in to its virtual servers and services. For security reasons the connection to the HCT cloud from 
outside the HCT premises is disabled. This gives the students an extra layer of data security and privacy. The internet port can be activated on the cloud anytime if it's needed. The HCT cloud gave the students tremendous amount of benefits while pursuing their studies. These benefits can be listed as follows: using iPads instead of desktop or laptop PCs therefore centralizing all their work and materials in one light portable device (convenient learning anywhere anytime), working on the latest Operating System platform and using any application software required for their studies without worrying about the compatibility issues, improving student data security by centralizing storage and maintaining it with the latest fault tolerance and data backup techniques on the HCT cloud storage area, students can do all their work electronically and paperless, students can enhance consistency and efficient communication by working collaboratively on the same project using single login accounts. At the same time, the HCT cloud is giving the administration and teaching faculties many benefits that can be listed as follows: flexibility of choosing the curriculums and software that best fit the needs of the students without worrying about mobile devices compatibility issues, easier installation/upgrading and sharing of applications/Operating Systems, reduced software licensing prices, hardware including wireless devices life cycle and maintenance are greater because resource-heavy applications run centrally, Ability to create a virtual local social network that is privately limited to selected students and controlled by the HCT team, ensures that access to courseware is widely accessible by students and easily controlled by administration, reduced bandwidth requirements for colleges wireless network, quick deployment of hardware/software, since all processing and maintenance happen centrally on the HCT cloud servers there are less technical troubleshooting for students devices which in terms means more time for the Technical and Support Team (TSD) to work on more productive and advanced enhancement for the college systems, and finally the ability to easy expend depending on need.

\subsection{Examples of Cloud Solution Usage Within CIS Department}

\subsubsection{Teaching Networking Courses}

The core contents of any CISCO based course running in the HCT orbits around the usage of Cisco Network Academy. The HCT networking students integrates all CISCO courses within their standard lab studies. Unfortunately all iOS devices don't support CISCO materials and Cisco network academy simulations. On the other hand, CISCO materials works smooth on all windows operated platforms. As a result, all students with iPads who wishes to study their CISCO courses using their tablets can overcome this problem by login in to the HCT cloud using their normal HCT credentials and choose the windows 7 image from the list of virtualized Operating Systems and download all the CISCO materials and start their work. Currently there are 2 courses (Basic Networking and Networking Security) running on the cloud and students are working on CISCO Network Academy and doing their projects using CISCO packet tracer directly through their iPad tablet devices through the HCT cloud.

\subsubsection{Teaching Multimedia Courses}

There are currently 3 multimedia courses running on the HCT cloud, allowing students to access multimedia applications using their iPads (Internet Multimedia \& Interactivity, 
Introduction to multimedia, and Web technologies) all of the above mentioned courses require the usage of specialised multimedia software packages that are not available in the app store or they can be only accessed using the developer own cloud solution. For example the software "Light wave" is required to build students' knowledge in 3D animation and it's not available as complete bundle on the iOS platform. Other software packages such as ADOBE suites are only available on the developer own cloud and cost tremendous amount of money for every user licence. To solve this issue, our multimedia students are using their iPads to login to the HCT cloud and access the Windows 7 image where the entire ADOBE suite and other multimedia software are installed per server agreements. This gives the students the freedom to work on software and applications such as Flash, Fireworks, light wave and Photoshop using their iPads with no limitations whatsoever. Once the students are finished with their work, they are either storing the work on the designated storage place assigned to them on the cloud or on any third party cloud storage system (Just Cloud, Drop Box, Box, etc.)

\subsubsection{Teaching Operating System and Security Courses}

It's practically impossible to remove the iOS and run any other operating system on the iPad tablets. Moreover, since all the security courses in the HCT depend in its lab manuals on running, troubleshooting and configuring many Operating Systems from multiple vendors and developers, this cause a major issue for running these courses labs using the iPad. As a solution for this problem, HCT security students are required to log in to the HCT cloud using their iPads and choose the Linux SUSE image from the list of OS's that was virtualised and running on the main cloud server. Once students are log in they can start working on configuring and troubleshooting the security options as required by their lab manuals. Currently there is only one course (OS security) that is piloting the cloud to simulate Linux SUSE operations.

\subsubsection{Teaching Basic Application Software Courses}

Currently there are 2 courses (Information Systems and Application Development) running on the cloud and students are logging in to the windows 7 image and starting the Microsoft Office application and working on MS word and MS excel using their iPads. The students of both courses were involved in an end of semester project workshop where they had to run their costumed made MS excel applications on their iPads and showcase their work to their peer students. Here's a list of some of the applications that were showcased: online airline reservation system, online grocery ordering system, cinema reservation system, etc...

\subsubsection{Using the HCT Cloud as a Massive Secure Central Storage System}

Once HCT students profile is created on the local cloud and a virtual machine is assigned to that profile, students are provided with $20 \mathrm{~GB}$ of private cloud storage. In cases students request an additional storage location; they are usually supplied with an extra $100 \mathrm{~GB}$. Storage allocation for students is dependent on their requirements and it's highly customizable. At the same time, students can rest for sure that their data are stored securely and reliably on the HCT cloud for the following reasons: 
- The HCT cloud is a private system solution that means only students, faculties and employees of the HCT can access it. The internet port is closed which means internet users are physically not allowed to access the solution, therefore outside hackers can't find a way to the student's data.

- Data on the HCT cloud storage are all stored with Redundant Array of Inexpensive Disk (RAID5). This allows maximum redundancy for storing files and makes it nearly impossible to loose data due to hard disks failure. All data are stored in multiple copies across the 48 physical hard disk drives on the HCT private cloud.

- DATA is regularly backed up into different storage devices back on the HCT main network drives.

- The main server is configured with the latest antivirus software (Symantec end point protection) and updated regularly for maximum protection.

- The HCT cloud solution is connected to the HCT main domain controller therefore all students data on the cloud is secured with the same credentials student use for their HCT authentications.

\subsubsection{Using the HCT Cloud as a Mean for Research}

Senior students in the HCT are working on the cloud in order to conduct research and offer recommendation for future enhancements. For example, last semester two groups of students from the CIS department offered technical presentations in both GITEX, Dubai (Cloud solution Confex), and ANKABUT, Abu Dhabi User's Event Cloud Congress. Presentations covered all aspects of HCT cloud usability and infrastructure of cloud computing within higher education. In both occasions the students prepared an in-depth presentation on the security and benefits of cloud solutions in mobile learning environment and used the HCT cloud as a study case.

\section{Student Acceptance}

At the end of September 2014, there will be an approximate of 120 students who are using and sharing the HCT cloud virtual machines. Students are divided among three campuses in Abu Dhabi and Khalifa city. Since the currently overall total number of concurrent licenses allowed in the HCT is 100 virtual machines, some students are sharing accounts under one virtual machine credentials with other peer students. Other senior students who are conducting research and performing testing on the cloud solutions are given individual accounts. At this point a group of 16 senior students who are given access to the cloud solution were surveyed to determine their level of satisfaction and acceptance of the new solution. The survey was delivered through Freeonlinesurveys.com and consisted of two parts. The first part comprised questions about the general usability of the HCT cloud solution as supplementary tools in concurrence with the usage of the iPad's. The second part consisted of questions tackling the general benefits of the HCT cloud solution in terms of storage, security and general usability. Students responded to the survey anonymously. The first part of the survey was specifically created to test the level of student's satisfaction in areas that is 
connected to using the clouds in college daily activities in correspondence to the usage of the iPad. All the 16 students in the surveyed group answered to the survey. The results of the survey were manually entered into Microsoft excel sheet and analyzed using statistical tools. In general the survey showed that most of the participants were extremely satisfied with the new cloud solution and found it very helpful in conjunction with using their iPads. Following is a summary of the survey results: $96 \%$ of all the respondents expressed that they log in to the HCT cloud every time they are in the HCT, while 6\% showed that they don't log in that regular. $100 \%$ of the respondents expressed that the HCT cloud solution is extremely helpful in their studies while using the iPad. Overall, $100 \%$ of the respondents expressed that they faced many limitations while studying to their courses in general while using the iPad prior to the implementation of the HCT cloud solution. All the respondents expressed that they would rather use iPads in conjunction with the HCT cloud rather than using their laptops alone. Overall, $87 \%$ of respondents expressed that they found the HCT cloud solution usefulness and user friendliness extremely satisfying, while $13 \%$ were moderately satisfied from the solution. Students were asked several questions related to their general usage of current technology in the HCT prior to introducing the HCT cloud solution; the results were empirical to determine the actual need of such cloud solution in the HCT. Statistics showed that the $31 \%$ of respondents lost their entire hard disk data at least once during their studies in the HCT, while $69 \%$ had lost some data. In this respect, the majority of the students shifted their hard disk storage usage from their local laptop drives into the HCT cloud solution, with $75 \%$ answering that they are regularly using the HCT cloud solution storage area assigned to them compared to $19 \%$ who answered that they are not using the HCT cloud storage, only $6 \%$ stated that they are sometimes using the cloud storage. Following are some data representations of the survey:

\begin{tabular}{|c|c|c|c|c|c|}
\hline & & $\begin{array}{l}\text { Extremely } \\
\text { satisfying }\end{array}$ & $\begin{array}{l}\text { Moderately } \\
\text { Satisfying }\end{array}$ & $\begin{array}{l}\text { Not that } \\
\text { easy }\end{array}$ & $\begin{array}{l}\text { very } \\
\text { Difficult }\end{array}$ \\
\hline \multirow[t]{2}{*}{ Q1 } & $\begin{array}{l}\text { How do you rate the HCT } \\
\text { cloud in terms of usage } \\
\text { and user friendliness? }\end{array}$ & $69 \%$ & $31 \%$ & 0 & 0 \\
\hline & \multicolumn{4}{|c|}{$\begin{array}{l}\text { How do you rate the HCT cloud in terms } \\
\text { of usage and user friendliness? } \\
\text { Moderately } \\
\text { Satisfying } \\
13 \%\end{array}$} & \\
\hline
\end{tabular}




\section{Macrothink}

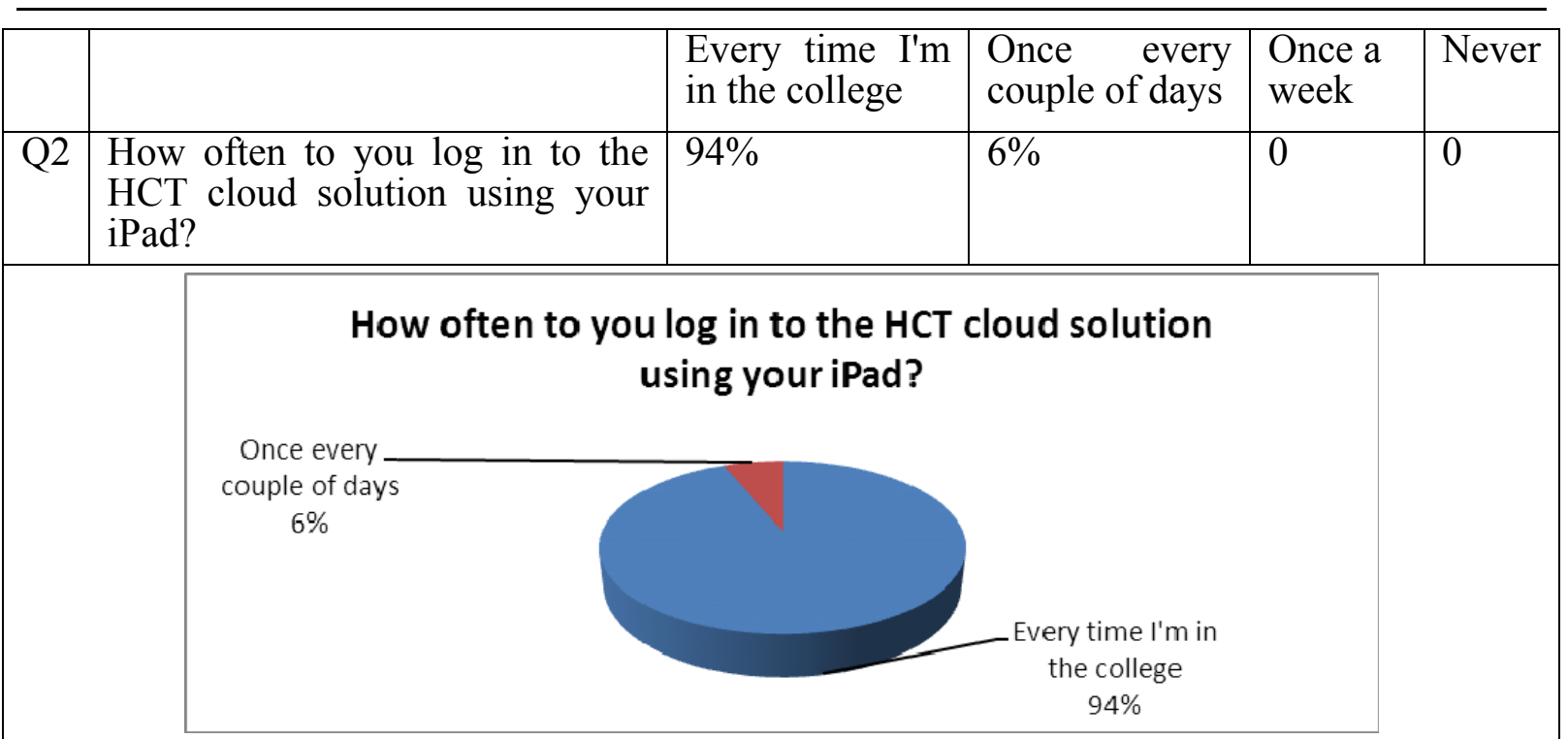

\begin{tabular}{|c|c|c|c|}
\hline Question & & $\begin{array}{l}\text { Laptop } \\
\text { alone }\end{array}$ & $\begin{array}{l}\text { iPad \& cloud } \\
\text { solution }\end{array}$ \\
\hline Q3 & $\begin{array}{l}\text { Would you rather use your laptop alone or } \\
\text { iPad/HCT cloud solution }\end{array}$ & $100 \%$ & $0 \%$ \\
\hline & $\begin{array}{l}\text { Would you rather use your laptop } \\
\text { or iPad/HCT cloud solution } \\
\text { Laptops } 0 \%\end{array}$ & alone & \\
\hline
\end{tabular}

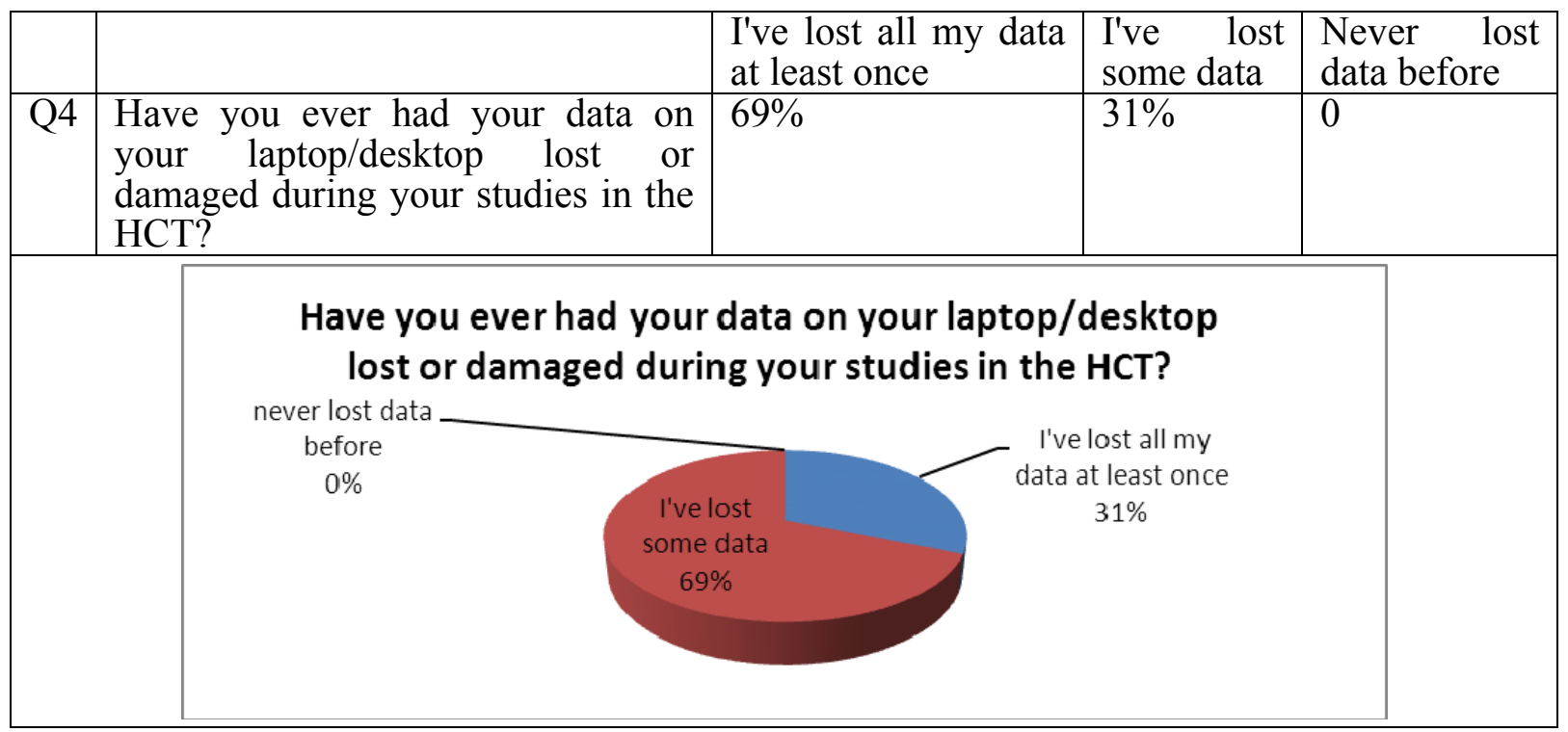




\begin{tabular}{|c|c|c|c|c|}
\hline Question & & Yes & No & $\begin{array}{l}\text { Sometim } \\
\text { es }\end{array}$ \\
\hline Q1 & $\begin{array}{l}\text { Do you find the HCT cloud solution helpful in } \\
\text { your studies while using your iPad? }\end{array}$ & $100 \%$ & $0 \%$ & NA \\
\hline Q2 & Do you use iPad in your studies in the HCT? & $100 \%$ & $0 \%$ & NA \\
\hline Q3 & $\begin{array}{l}\text { Do you face any problem(s) using the iPad to } \\
\text { study for your Multimedia courses? (Prior to the } \\
\text { HCT cloud) }\end{array}$ & $94 \%$ & $6 \%$ & NA \\
\hline Q4 & $\begin{array}{l}\text { Do you recommend expanding the HCT cloud to } \\
\text { include all your courses? }\end{array}$ & $100 \%$ & $0 \%$ & NA \\
\hline Q5 & $\begin{array}{l}\text { Are you using the private HD storage assigned to } \\
\text { your account on the HCT cloud instead of using } \\
\text { your laptop local drive? }\end{array}$ & $75 \%$ & $19 \%$ & $6 \%$ \\
\hline
\end{tabular}

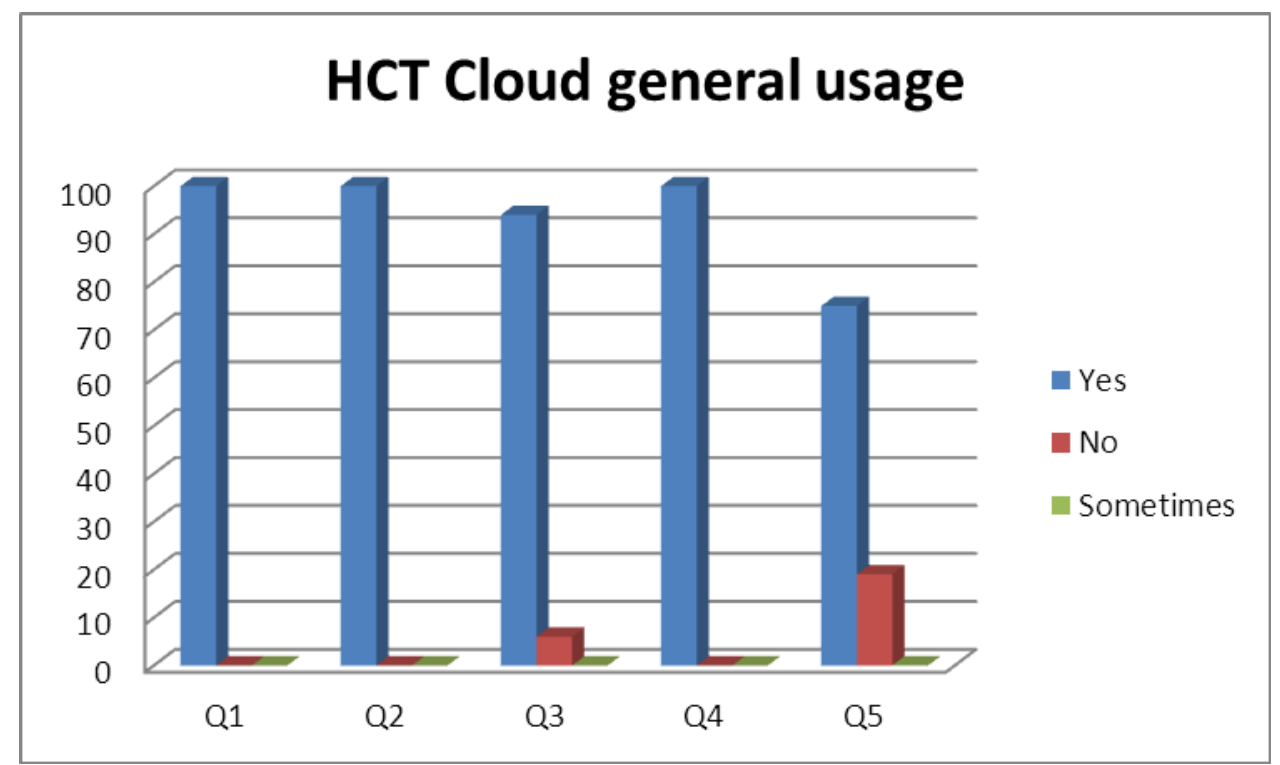

\section{Technical Information on the VDI Solution and Future Expansion Planes}

The HCT cloud solution consists of the following hardware/software:

1. A 42U slandered 19” Rack to host all the cloud hardware. $(\$ 1,199)$

2. 2 racks of Hard disks stands, each rack accommodate 24 physical hard disk drives and each hard disk has a 600 Gigabyte's storage capacity. All hard disks come with high performance, 1500 round per seconds, and redundancy support.(\$80 for each hard disk)

3. HCT Cloud Server: The HCT is using HUAWEI enterprise level main blade server (T6000) (with virtualization support system). The server is used for management, computing and storage purposes. It accommodates an Intel Xeon 5600 serious with 8 core processors. There are currently 32 GB DDR3 memory installed and the baled system supports up to 12 DIMM slots with total 96GB DDR3 memory. (7,400\$) 
4. The blade server supports full redundancy for maximum data security and is designed to avoid single-node failures. Also the system adapts the passive backplane design to improve system reliability. This gives the students extra storage security and data protection.

5. Two HUAWEI Access switches (S5352C-EI module) each with 48 ports. The switches are currently not connected to the default college internet gateway server; as a result the solution is strictly accessed by users who reside physically inside the 17 colleges within the HCT premises. To allow the cloud solution to be accessed via internet for future expansion plans all what need to be done is to connect the switch to the default HCT internet gateway. The switches are connected to the blade server that is in turn connected to the hard disk storage system and are all linked to the main domain server in the HCT. Therefore the students are allowed to log in to the HCT cloud using their predefined username and password that is normally used for their college access. (\$990 per switch)

For a comprehensive overlook at the HCT cloud solution topology please take a look at figure 1.1 at the end of this paragraph.

6. The Huawei hardware comes with three main software utilities to configure and management the cloud solution. Following is a list of the software used:

a. Single Cloud GalaX: it's complete bundle software that is developed by HUAWEI to allow the implementation of the virtual computing functions, networking, imaging, and storage management. All these utilities are available using an extremely user friendly web Graphical User Interface. Using this web GUI the cloud administrators can create/delete virtual machines (VM), and attach/detach VM to users. Also this utility allows the creation of Hard Disk volumes and attaching/detaching it to specific virtual machine's users. Moreover, using the single cloud GalaX, hardware virtualization can be achieved that is a group of utilities that allows the hardware installed on the cloud to be configured logically and clustered among many users as needed. For example, all senior students working on the HCT cloud are given more computational and RAM allocation to their virtual machines more than regular users who are currently involved in studying application software courses and working on MS word and Excel. This option in fact allows the administrator to better tailor and utilize the cloud resources and optimize hardware efficiency. Also part of this software is the virtualization platform that is the main tool that is used for uploading the "iso" images and virtualizing it to be used by the HCT cloud users. The system administrator can use these configuration management utilities to add new images to the HCT cloud solution. Currently in the HCT private cloud we have two OS images uploaded, windows 7, and Linux SUSE. Both operating systems were imaged fully loaded with application packages that students need during their studies. For example, ADOBE suite, MS office, CISCO network academy, etc..

b. Single Cloud VDesktop: This is an in house HUAWEI access application that gives the essential interface between the HCT cloud users and the 
virtualization server and its services. Moreover, this utility is used to implement session connection management that allows the 60 Thin Clients (TC) installed among the colleges to access the blade server.

c. Single Cloud OM system: This utility is used to generate maintenance reports and users status. It's also used to monitor the overall performance of the HCT cloud solution and generate operation log menu.

Currently the end-to-end Huawei configuration supports up to $100 \mathrm{VDI}$, expandable on request, including servers, storage, network, security and thin clients. There are 60 thin clients consisting of a receiver box, mouse, keyboard and 21 inch monitor. The thin clients are distributes across three labs in Abu Dhabi (Khalifa Campus Women College, Abu Dhabi Women's College, and one lab in Abu Dhabi Men's College) all labs are centrally connected to the HCT single cloud rack that is located physically in the Technical and Support Department in Abu Dhabi Women's College. All administrative configuration and upgrades is done remotely using the HUAWEI web based management system. Currently there is a plan to expend the VDI network to install TC's labs in all the other HCT colleges and to expend the simultaneous licenced VM's from 100 to 1000 users.

Step by step manual to use the HCT cloud services:

\section{a. Install new Virtual Image on the blade server}

- Log in to the virtualization services using the following URL (https://10.12.38.18) with administrative username and password

- Download any File Transfer Protocol on your machine. ( we recommend using Win $\mathrm{SCP}$, its free and available on the internet)

- Create an ISO image of your new operating system and use the FTP to upload it to the server /opt/image folder

- Log in to the single cloud O\&M system using the following URL (https://10.12.38.18/OMSportal)

- Go to the configuration window and access the image management menu and click on "create new image"

- Enter the specification of hard disk space and choose your intended operating system type to be uploaded, make sure to specify the correct location of the file (/opt/image) and start the process of image creating.

- At this point the image needs to be moved to the main blade server "temp" folder. To do that use any telnet client (we recommend using Putty, that is open source and free from the internet)

- After moving the image to the temp folder it needs to be moved finally and activated on the image/bukkits to be available and accessible by all the users, this should take from 1 to 3 hours depending on the type and size of the new operating system image. 


\section{Macrothink}

\section{b. Create Virtual Machines and attach them to users.}

- Access the cloud computing services management system using the following URL (https://10.12.38.31:8081/itac and log in using administrative credentials

- Click on the VM option and create a new VM button

- Fill in the VM specifications (user ID, allocated hard disk space, image ID, network card type, for the Cluster name and VPC ID choose the default) than click OK

- In 5 to 10 minutes the new VM will be created all what you need to do at this point is to assign the VM to a user

- Choose the VM and click on the attach VM to user option

- Enter the domain account name of the user and user will be officially attached to the new virtual machine.

\section{c. Enable HCT cloud on mobile devices:}

- Download the free software "CITRIX" from either Google play (android devices) or app store on iOS devices and configure the receiver to connect to the server where the image you intend to access is located.

- In this example the windows 7 image is located on the following URL (http://10.12.38.33 ) and domain name should be "HCTAD", use same credentials as used to login to the HCT account.

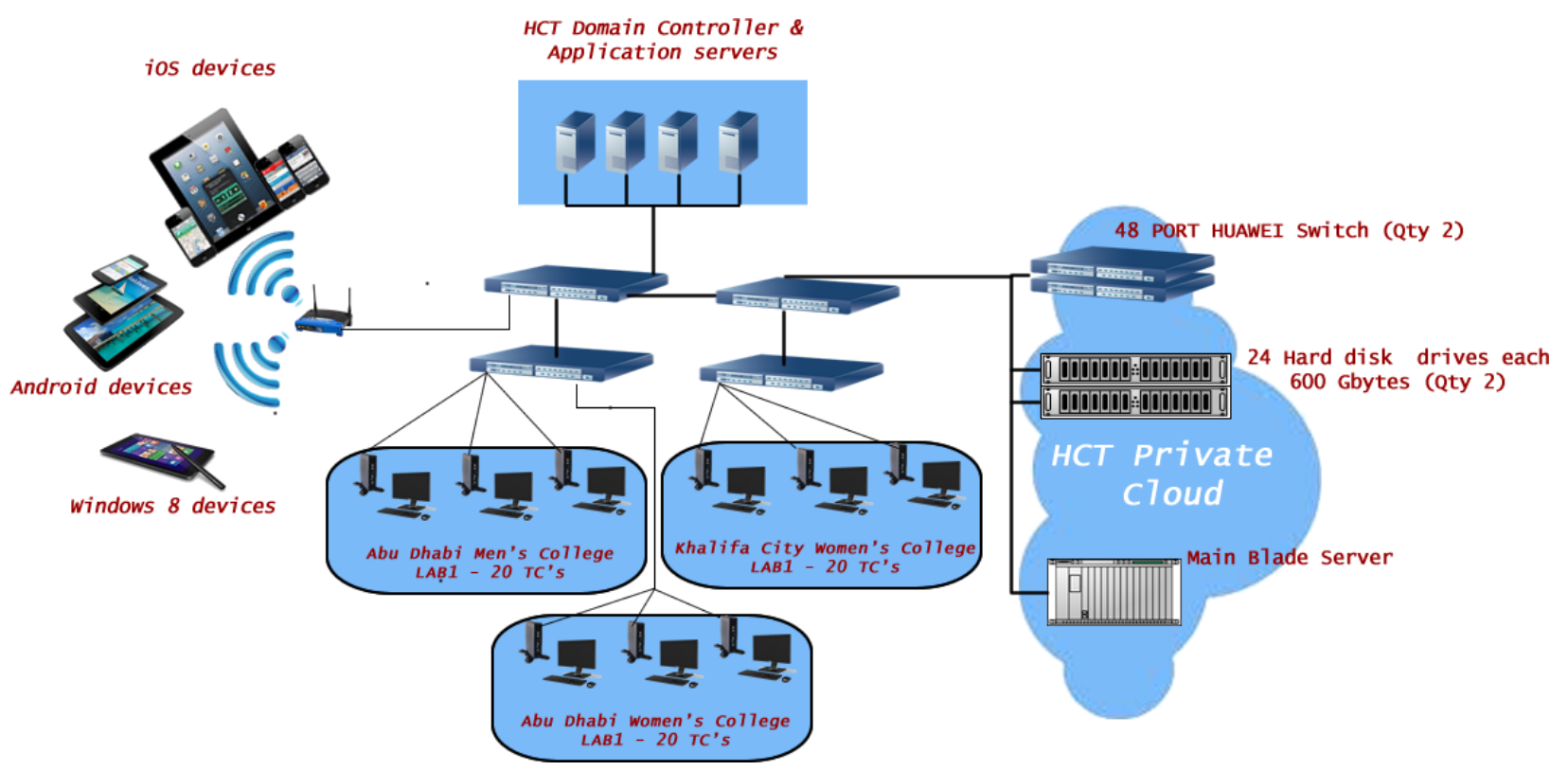

Figure 1.1 HCT Cloud solution topology 


\section{VDI Cloud Utilisation at HCT and Cost Benefit Study}

According to Koomey (2011), "It's cheaper for bigger cloud computing folks to make efficiency improvements because they can spread the costs over a larger server base and can afford to have more dedicated folks focused on efficiency improvements"(p.2). As new campuses within the HCT system starts using the cloud, the cost benefits of the new solution will be more justifiable. It's a fact that the cost of the preliminary establishment of the HCT cloud infrastructure can be a bit expensive but as more users start joining the cloud, the cost per user will start declining and the benefits will be highlighted. At this point, the HCT private cloud is proving to be an extremely cost effective solution with a possibility of expansion across all over the 17 campuses of HCT in the UAE. This cloud solution can minimize both the hardware and software cost used for teaching, including the technical support maintenance overhead time and cost. For a detailed comparison in terms of utilization and cost benefit between the cloud system and the traditional system in the HCT please take a look at the below table:

Table 1. HCT traditional vs cloud system comparison table

\begin{tabular}{|c|c|}
\hline Current System & ICT private cloud system \\
\hline $\begin{array}{l}\text { Every student working in the labs need a } \\
\text { dedicated computer, in certain courses the } \\
\text { specification of the computer needs to be } \\
\text { high end to support the overhead processing } \\
\text { power some application needs, for example } \\
\text { ORACAL and multimedia courses they all } \\
\text { need an extremely powerful CPU with large } \\
\text { RAM capacity. The average computer needed } \\
\text { to support these applications cost between } \\
\$ 1,100 \text { to } \$ 1,500 \text {. }\end{array}$ & $\begin{array}{l}\text { Every student working in the cloud dedicated } \\
\text { labs need a monitor, keyboard and a thin } \\
\text { client. All the processing of application } \\
\text { happens at the back end within the blade } \\
\text { server. As a result the average cost of having } \\
\text { one station regardless of the application } \\
\text { needed to run on it is } \$ 200 \text { with the } \\
\text { possibility of adding extra thin clients with } \\
\text { minimum effort. }\end{array}$ \\
\hline $\begin{array}{l}\text { Students in many cases use their laptops to } \\
\text { install all sorts of applications necessary for } \\
\text { their course studies. These applications are } \\
\text { licensed per person usage and usually there } \\
\text { are limited amount of licenses within each } \\
\text { college. Therefore students are forced to } \\
\text { uninstall the software at the end of each } \\
\text { academic semester so that other users can be } \\
\text { licensed to use it. For example, with Adobe } \\
\text { Creative cloud each student has to pay } \\
\$ 19.99 \text { per month to access the Adobe cloud } \\
\text { solutions with all the software. Alternatively } \\
\text { you can pay after educational discount } \\
\text { around } 600 \$ \text { per machine to purchase the }\end{array}$ & $\begin{array}{l}\text { To buy a multi instance per server license } \\
\text { that allows students to use the Adobe suite } \\
\text { fully on their Thin Clients or mobile devices } \\
\text { this will cost } \$ 7,500 \text {. In this respect and with } \\
\text { comparison to the } \$ 19.99 \text { ADOBE plane to } \\
\text { use their cloud network this will cost the } \\
\text { college for the } 900 \text { students around } \$ 17,991 \text {. } \\
\text { On the other hand with the per server } \\
\text { installation the cost of using the HCT private } \\
\text { cloud and giving access to students will be } \\
\text { almost } \$ 8.33 \text { per student. This shows the } \\
\text { great amount of money that can be saved by } \\
\text { using the HCT cloud solution to buy per } \\
\text { server or per multiple servers and distribute }\end{array}$ \\
\hline
\end{tabular}


license of the complete Adobe Photoshop. virtually to students.

With an institute like the HCT there are more than 900 active users every semester that needs to work on ADOBE for their multimedia studies that puts this software alone with cost over $\$ 17,991$.

The technical and support department in the HCT are over their heads all the times trying to accommodate the requests of installing/reinstalling and repairing damaged software and hardware. Moreover, during specialized programs such as security courses a specific operating system will need to be installed or imaged on each student's machine at the beginning of the semester. All of this takes great time and effort from the TSD department that can be invested in other more long term productive endeavours. At the same time, all the installations and imaging on the student's machines and college's labs puts an overhead processing time and usage that makes the hardware and networking infrastructure life cycle shorter.

Students usually save their work and study data locally using their laptops on their hard disks either internally or externally. In many cases, and as the survey showed in the section above, students tend to lose their data due to mishandlings of their storage devices or due to viruses and external factors quite often. An average 500 Gigabytes external hard disk cost $\$ 150$ without any security or redundancy solution.

An average lab that consists of 20 standalone computers with average specifications will cost around $\$ 22,000$.

With the introduction of the HCT cloud solution all the virtual images and student's virtual machines needed to access the images are created once centrally on the blade server and students can $\log$ in with their TC's from the labs or mobile devices and enjoy the end results without the hassle of troubleshooting and maintenance locally on their devices. This has defiantly reduced the troubleshooting requests from the students who are currently using the cloud and made extra time for the TSD employees to invest in more research and productive activities.

With the introduction of the cloud system the students can use up to 28 Terabytes, can be extended to 172.8 Terabytes with all the redundancy and security standard in place to protect and make sure students will never lose their data for almost half the price of the old system. The HCT cloud system hard disk 600 GB will cost an average of $\$ 80$.

The actual price of the HCT cloud hardware is $\$ 13,429$ (the rack, blade server, switches and hard disks). HUAWEI gave the HCT free installation and support for the system. In comparison to the actual building of labs with standalone computers, it's obvious the amount of money that can be saved using such technology. 


\section{Conclusion}

Using mobile technology as a standalone tool in education has many limitations while combining it with the proper cloud solutions can overcome these issues and bring a more comprehensive resolution. Private cloud systems such as the HCT private single cloud which offers software and hardware virtualizations can bring tremendous amount of benefits to both mobile learning and teaching. The HCT cloud allows students and faculty members to use their smart devices or thin clients preinstalled machines to login to the cloud and enjoy all the benefits of virtualization. Students are using this technology to access software suites from their iPad that are usually not available on the app store or not supported by apple iOS platforms. The technology also is proving to facilitate both students and faculty members' ability to teach and learn more effectively in a mobile dynamic environment. At the same time, the new cloud solution is reducing the cost of building new hardware labs and infrastructure therefore making the process of education more accessible and convenient to students.

In summary, integrating cloud computing systems such as the HCT private cloud with mobile technology standards such as tablets and smart mobiles can form a great solution to pave the road toward a more comprehensive and dynamic modern educational system.

\section{References}

Cruise, L (2013). Mobile Internet Tops 12 Most Disruptive Technologies. The Network CISCO’s Technology News Site, 12, 3-4.

Katz, R. N. (2008). The Tower and The Cloud Higher Education in the Age of Cloud Computing. Campanile, University of California Berkeley.

Koomey, J. (2011). 4 reasons why cloud computing is efficient, GIGAOM Inc. Retrieved July 25, 2011, from http://gigaom.com/2011/07/25/4-reasons-why-cloud-computing-is-efficient

\section{Copyright Disclaimer}

Copyright reserved by the author(s).

This article is an open-access article distributed under the terms and conditions of the Creative Commons Attribution license (http://creativecommons.org/licenses/by/3.0/). 